\title{
Probiotic Supplementation and Fast Freezing to Improve Quality Attributes and Oxidation Stability of Frozen Chicken Breast Muscle
}

Hyun-Wook Kim, Danika K. Miller, Feifei Yan', Weichao Wang', Heng-wei Cheng $^{2}$, and Yuan H. Brad Kim*

Meat Science and Muscle Biology Laboratory, Department of Animal Sciences, Purdue University, West Lafayette, IN 47907, USA

${ }^{1}$ Department of Animal Sciences, Purdue University, West Lafayette, IN 47907, USA

${ }^{2}$ Livestock Behavior Research Unit, USDA-Agricultural Research Service, West Lafayette, IN 47907, USA

*Corresponding author: Yuan H. Brad Kim, Meat Science and Muscle Biology Laboratory, Department of Animal Sciences, Purdue University, 901 West State Street, West Lafayette, IN 47907, USA. Tel: +1 765496 1631. E-mail address: bradkim@purdue.edu 


\begin{abstract}
The study was conducted to determine the effects of probiotic supplementation and fast freezing on quality attributes and oxidation stability of frozen/thawed chicken breast muscle. Broilers $(n=168)$ were fed with a basal diet or the basal diet plus 250 mg of Sporulin (three strains of Bacillus subtilis) / kg of basal diet for 45 days. Pairs of breasts were separated from chicken carcasses and randomly assigned to either slow ($\left.30^{\circ} \mathrm{C}\right)$ or fast freezing $\left(-70^{\circ} \mathrm{C}\right)$ and stored at $-30^{\circ} \mathrm{C}$. After thawing at $2{ }^{\circ} \mathrm{C}$ for $24 \mathrm{~h}$, half of the thawed breasts from each treatment were stored for an additional $48 \mathrm{~h}$. Probiotic supplementation increased phospholipid content in breasts $(P<0.05)$, but substantially delayed both primary and secondary lipid oxidation products shown by the results from peroxide value and 2-thiobarbituric acid reactive substances $(P<0.05)$. Further, the breasts from probiotic chicken group had a significantly lower nonheme iron content than those from control chicken group. Fast freezing significantly reduced thaw/purge loss and minimized lipid oxidation $(P<0.05)$. Our results suggest that oxidative deterioration and increased purge/thaw loss of frozen chicken breasts can be effectively minimized by probiotic supplementation coupled with fast freezing.
\end{abstract}

Keywords: Bacillus subtilis, chicken breast, fast freezing, lipid oxidation, probiotics 


\section{Introduction}

Freezing is one of the most common preservation methods extending shelf-life of chicken meat products (Ali, Zhang, Rajput, Khan, Li, \& Zhou, 2015; Grunert, Stephan, Ehling-Schulz, \& Johler, 2016; Soyer, Özalp, Dalmış, \& Bilgin, 2010). While freezing effectively suppresses microbial growth and prevents chemical changes during storage, some defects of meat quality, such as discoloration, inferior water-holding capacity (WHC), and oxidation of lipid and protein, are well-identified challenges associated with freezing/thawing procedures (Ali et al., 2015; Soyer et al., 2010).

In general, meat quality changes in frozen/thawed meat occur during freezing and thawing processes ( $\mathrm{Li} \&$ Sun, 2002). The formation of ice crystals during freezing causes physical and structural damages to muscle tissues and/or cells, in turn, leading to various chemical reactions affecting quality attributes of frozen/thawed meat (Leygonie, Britz, \& Hoffman, 2012). In particular, lipid oxidation, which is one of major quality deteriorations in frozen meat products, is attributed to the release of prooxidants from muscle cells by ice crystal damage (Leygonie et al., 2012; Soyer et al., 2010). Freezing rates affect the size, location, and distribution of ice crystals, and consequently impact the extent of damage to muscle tissues and/or cells. Thus, it has been suggested that fast freezing could improve color characteristics, WHC (thaw and/or purge loss), and tenderness of frozen/thawed meat products by allowing the formation of small and uniform intracellular ice crystals (Mortensen, Andersen, Engelsen, \& Bertram, 2006). However, the effect of fast freezing on lipid oxidation stability of frozen/thawed meat has not been fully studied.

In the poultry industry, the supplementation of microbial dietary probiotics has been recently considered as an alternative way to substitute antibiotics, thereby 
improving chicken's intestinal homeostasis balance. This could contribute to positive impacts on chickens' feed intake and digestion, immune response, and resistance to disease (Kabir, 2009; Zhang, Zhou, Ao, \& Kim, 2012; Zhou, Wang, Gu, \& Li, 2010). Along with such advantages on chicken growth performance and health, the probiotic supplementation in feed or drinking water could improve the quality attributes of chicken meat, such as WHC, tenderness, oxidation stability, sensory properties and/or microbial growth (Ali, 2010; Liu et al., 2012; Pelicano et al., 2003,2005; Zhou et al., 2010; Zhang et al., 2012). Thus, it would be reasonable to postulate that probiotic supplementation can reduce or prevent the quality decline of frozen/thawed chicken meat products originated from the freezing/thawing processes. While frozen chicken is a very common type of meat product in the retail market, there is limited information regarding the effects of probiotic supplementation on oxidation stability and meat quality attributes of frozen/thawed chicken meat.

Taken together, we hypothesized that probiotic supplementation coupled with fast freezing will bring synergistic impacts on preventing the quality deterioration of frozen/thawed chicken meat by improving WHC and lipid oxidation stability. Therefore, the objective of this study was to determine the effects of probiotic supplementation (Bacillus subtilis) and fast freezing on quality attributes and oxidation stability of frozen/thawed chicken breasts during 0 and 2 days of refrigerated storage after thawing.

\section{Materials and methods}

\subsection{Animal management and sample collection}


One hundred and sixty-eight 1-day-old chicks (Ross 708 male broiler) were obtained from a commercial hatchery (Miller Poultry, Orland, IN), which were groupweighed and randomly placed in 12 pens at the Poultry Research Facility of Purdue University, based on their average body weight. The animal management procedures were approved by the Purdue Animal Use and Care Committee (PACUC Number: 1111000262). The pens were randomly assigned to two diet groups for 45 days as follows; basal diet for control group and the basal diet plus $250 \mathrm{mg}$ of Sporulin $(1.0 \times$ $10^{6} \mathrm{cfu} / \mathrm{g}$ feed, containing three strains of Bacillus subtilis) $/ \mathrm{kg}$ of basal diet for probiotic group. The information on the commercial probiotic product (Sporulin) was provided by the manufacturer (Pacific Vet Group-USA, Inc., Fayettville, AR, USA), and the feeding level followed the recommendations of the manufacturer. The formulation of basal diet was based on the recommendations for nutrients by the NRC (1994). The environment and feeding regimes was followed by the conditions described by Kim et al. (2016). On day 45, two birds were randomly taken from each pen, commercially harvested, and air-chilled in a $2{ }^{\circ} \mathrm{C}$ carcass room for $24 \mathrm{~h}$. Both sides of breast muscles (M. Pectoralis minor) were removed from each chicken carcass at 1 day postmortem, weighed, and individually vacuum-packaged in a polyamide/polyethylene bag.

\subsection{Freezing and thawing procedure}

Pairs of breast muscles were randomly assigned into two different freezing rates (slow and fast freezing), respectively. Slow freezing was performed in a $-30{ }^{\circ} \mathrm{C}$ conventional air freezer, whereas fast freezing was conducted in a liquid nitrogen chamber, where ambient temperature maintained at $-70^{\circ} \mathrm{C}(12 \mathrm{CF}$ cabinet freezer, $\mathrm{RS}$ 
Cryo Equipment Inc., USA). A decline in internal core temperature of the breasts was monitored until reached at $-20^{\circ} \mathrm{C}$ by using a digital temperature logger (OctTemp2000, MadgeTech, Inc., Warner, NH) with a thermocouple (T-type, Omega Engineering, Stamford, CT). After the freezing process, all frozen chicken breasts were immediately placed in the $-30{ }^{\circ} \mathrm{C}$ conventional freezer and stored for 12 months. The frozen chicken breasts were thawed in a $2{ }^{\circ} \mathrm{C}$ cooler for $24 \mathrm{~h}(0$ day of refrigerated storage after thawing), to determine extended storage effect on quality attributes of frozen/thawed breasts, and half of frozen/thawed samples from each treatment were continuously placed in the same cooler for additional $48 \mathrm{~h}$ ( 2 days of refrigerated storage after thawing). The frozen/thawed chicken breasts were blotted with a paper towel, weighed, and used for further analyses.

\subsection{Analyses of frozen/thawed chicken breasts}

\subsection{1. $p H$}

Three grams samples of frozen/thawed chicken breasts were taken from the same location and homogenized with $27 \mathrm{ml}$ of distilled water (DW) using a homogenizer (Ultra-Turrax T25, Janke \& Kunkel IKA-Labortechnik, Staufen, Germany) at 6,000 rpm for $30 \mathrm{~s}$. The $\mathrm{pH}$ value of frozen/thawed chicken breasts was determined in triplicate using an electronic pH meter (Sartorius Basic Meter PB-11, Sartorius AG, Germany).

\subsubsection{Thaw/purge loss}

Thaw/purge loss $(\%)$ of frozen/thawed chicken breasts was determined by calculating the differences in the weight before freezing and after thawing. 


\subsubsection{Centrifugal WHC determination}

WHC of frozen/thawed chicken breasts was determined in duplicate according to the centrifugal method described by Kim et al. (2016). The WHC (\%) was estimated by calculating the percentage breast weight before and after centrifugation; WHC (\%) $=($ sample weight after centrifugation $(\mathrm{g}) /$ sample weight before centrifugation $(\mathrm{g})) \times$ 100.

\subsubsection{Instrumental color measurement}

Surface color (five random locations on bone side) of frozen/thawed chicken breasts was determined using a Hunter MiniScan EZ colorimeter (Hunter, Reston, VA, USA) equipped with a $25 \mathrm{~mm}$ (diameter) measuring. The setting for the illuminant was D65 source and the observer was standard $10^{\circ}$. Calibration of the instrument was conducted using black and white calibration tiles, according to the standard manual. CIE $L^{*}, a^{*}$, and $b^{*}$ values were recorded. Hue angle values were calculated using the following equation; hue angle $=\tan ^{-1}\left(b^{*} / a^{*}\right)($ AMSA, 2012) .

\subsubsection{Lipid extraction and content}

To determine lipid content, peroxide value, and phospholipid content, lipid fraction was extracted from frozen/thawed chicken breasts using a chloroform/methanol solvent system (2:1, ml:ml) (Lee, Trevino, \& Chaiyawat, 1996). The lipid content per sample was determined in triplicate according to the procedure described by Soyer et al. (2010). Five grams of chicken breast was homogenized with $50 \mathrm{ml}$ of the chloroform/methanol solvent in a Waring blender. The mixture was 
filtered through filter paper (Whatman No. 1), and the filtrate was divided into two layers using $20 \mathrm{ml}$ of $\mathrm{NaCl}$ solution $(0.5 \mathrm{~g} / 100 \mathrm{ml})$. The chloroform phase was taken, and chloroform was evaporated on a hot plate. Lipid content was calculated as follows; lipid content $(\%)=[($ amount of extracted lipid $(\mathrm{g}) /$ sample weight $(\mathrm{g})) \times($ volume of chloroform $(\mathrm{ml}) / 10 \mathrm{ml}) \times 100]$.

\subsubsection{Peroxide value (POV)}

POV of frozen/thawed chicken breasts was determined in duplicate following the method of the International Dairy Federation (IDF) described by Soyer et al. (2010). The extracted lipid fraction $(150 \mathrm{mg})$ was placed in a disposable glass tube and mixed with $9.8 \mathrm{ml}$ of the chloroform/methanol solvent mixture. After vortex-mixing for $5 \mathrm{~s}$, $50 \mu \mathrm{l}$ of ammonium thiocyanate solution $(30 \mathrm{~g} / 100 \mathrm{ml})$ was added to the glass tube and vortex-mixed again for $5 \mathrm{~s}$. Then, $50 \mu \mathrm{l}$ of iron (II) solution (Shantha \& Decker, 1994) was immediately added, vortex-mixed for $5 \mathrm{~s}$, and incubated at room temperature for 5 min. The absorbance of the mixture was read at $500 \mathrm{~nm}$ using a spectrophotometer (VWR International, OR, USA), and POV was expressed as milliequivalents of peroxide per $\mathrm{kg}$ fat (meq $\mathrm{O}_{2} / \mathrm{kg}$ fat).

\subsubsection{Phospholipid content}

The phospholipid content of frozen/thawed chicken breasts was determined in duplicate according to the method of Stewart (1980) described by Eymard, Carcouët, Rochet, Dumay, Chopin, and Genot (2005). The extracted lipid fraction was diluted to $0.25 \mathrm{mg} / \mathrm{ml}$ using chloroform and placed in a $15 \mathrm{ml}$ centrifuge tube. One milliliter of thiocyanate reagent was added to the tube and vortex-mixed for $30 \mathrm{~s}$. The mixture was 
centrifuged at $750 \times \mathrm{g}$ for $10 \mathrm{~min}$, and the absorbance of the supernatant (from lower phase in the tube) was read at $488 \mathrm{~nm}$. Standard curve was prepared with phosphatidylcholine/chloroform solution $(5-50 \mu \mathrm{g} / \mathrm{ml})$. The phospholipid content was expressed as g phosphatidylcholine equivalents per $\mathrm{kg}$ fat ( $\mathrm{g}$ phosphatidylcholine eq/kg fat).

\subsubsection{2-Thiobarbituric acid reactive substances (TBARS)}

The TBARS value of frozen/thawed chicken breasts was determined in duplicate according to the method of Buege and Aust (1978) described by Kim et al. (2016). Five grams of sample was homogenized with $15 \mathrm{ml} \mathrm{DW}$ and $50 \mu \mathrm{l}$ of butylated hydroxyl anisole solution $(10 \mathrm{~g} / 100 \mathrm{ml})$ in ethanolic solution $(90 \mathrm{ml} / 100 \mathrm{ml})$ using the Ultra Turrax at 13,000 rpm for $30 \mathrm{~s}$. One milliliter of the homogenate was mixed with $2 \mathrm{ml}$ of $20 \mathrm{mM}$ 2-thiobarbituric acid (TBA) solution in trichloroacetic acid (TCA) solution $(15 \mathrm{~g} / 100 \mathrm{ml})$. The mixture was heated for $15 \mathrm{~min}$ in a water bath $\left(80{ }^{\circ} \mathrm{C}\right)$, cooled for $10 \mathrm{~min}$ in ice, and centrifuged at 2,000 $\times \mathrm{g}$ for $10 \mathrm{~min}$, then filtered through filter paper (Whatman No. 4). The supernatant was placed on 96-well plate; and the absorbance was measured at $538 \mathrm{~nm}$ using a microplate spectrophotometer (Epoch, Biotek Instruments Inc., VT, USA). A blank was prepared with $2 \mathrm{ml}$ distilled water and $4 \mathrm{ml}$ TBA/TCA solution. The TBARS was expressed as mg MDA per $\mathrm{kg}$ meat (mg MDA/kg meat).

\subsubsection{Nonheme iron content}


Nonheme iron content of frozen/thawed chicken breasts was determined in duplicate by following the ferrozine method (Ahn, Wolfe, \& Sim, 1993). The nonheme iron content was expressed as mg nonheme iron per $100 \mathrm{~g}$ meat $(\mathrm{mg} / 100 \mathrm{~g})$.

\subsection{Statistical analysis}

The experimental design of this study was spilt-split-plot design, where the whole-plot was for each chicken carcass from two diet treatments (control and probiotic groups), the sub-plot was for each side of chicken breast meat assigned to two freezing rates (slow and fast freezing), and the sub-sub-plot was for the frozen chicken breasts randomly assigned for two different storage periods after thawing ( 0 and 2 days). All data were analyzed using the PROC MIXED procedure of SAS 9.4 software (SAS, 2012). Least squares means for all traits were separated (F test, $P<$ 0.05) by using least significant differences generated by the PDIFF option.

\section{Results and discussion}

\subsection{Temperature decline}

The temperature decline of chicken breasts assigned to either slow or fast freezing is presented in Fig. 1. Freezing rate plays a critical role in forming ice crystals, which is primarily responsible for structural damages to muscle tissues and/or cells. In general, the pattern of ice crystal formation (e.g. size, location, and shape) is determined by passing time through initial freezing point $\left(-1.5\right.$ to $\left.-7^{\circ} \mathrm{C}\right)$, where nearly $80 \%$ of the water in meat is frozen (Kim, Liesse, Kemp, \& Balan, 2015). According to Añón and Calvelo (1980), fast freezing (defined as passing the initial freezing point within $10 \mathrm{~min}$ ) leads to the formation of intracellular ice crystals in muscle fibers. In 
this current study, the time to pass the initial freezing point of chicken breasts assigned to fast and slow freezing rates was approximately $3.5 \mathrm{~min}$ and $527 \mathrm{~min}(8.8 \mathrm{~h})$, respectively. Further, to reach the final targeted freezing temperature $\left(-18{ }^{\circ} \mathrm{C}\right)$ from $1.5^{\circ} \mathrm{C}$, chicken breasts assigned to fast freezing took $7.5 \mathrm{~min}$, whereas those assigned to slow freezing took $1,033 \mathrm{~min}(17.2 \mathrm{~h})$. Therefore, the chicken breast muscles assigned to the fast freezing would likely have much smaller and uniform intracellular ice crystals compared to the chicken breasts assigned to slow freezing counterparts.

\section{2. $p H$ and $W H C$}

The effects of probiotic supplementation and fast freezing on $\mathrm{pH}$ and $\mathrm{WHC}$ (thaw/purge loss and centrifugal WHC) of frozen/thawed chicken breasts at 0 and 2 days after thawing are shown in Table 1 . The $\mathrm{pH}$ of frozen/thawed chicken breasts was affected by probiotic supplementation, storage after thawing, and their interaction $(P<$ 0.05). The $\mathrm{pH}$ of breasts from probiotic chicken group (5.91) was significantly lower than those from control chicken group (6.02). Similarly, Ali (2010) reported that breasts (5.76) from Bacillus subtilis fed broilers had a significantly lower $\mathrm{pH}$ than those from broilers without probiotic feeding (6.00). Refrigerated storage after thawing decreased the $\mathrm{pH}$ of frozen/thawed chicken breasts. In particular, a significant decrease in $\mathrm{pH}$ was found at breasts from the control group. This result might be due to the release of hydrogen ions from denatured proteins during extended storage after thawing (Leygonie et al., 2012). As a result, the $\mathrm{pH}$ value of all frozen/thawed chicken breasts was similar after 2 days of refrigerated storage after thawing $(P>0.05)$, regardless of probiotic supplementation and freezing rates. 
The probiotic supplementation had no influence on thaw/purge loss and centrifugal WHC of frozen/thawed chicken breasts $(P>0.05)$. Previous studies reported no impact of Bacillus subtilis feeding on WHC of chicken muscles (Kim et al., 2016; Pelicano et al., 2003,2005; Zhang et al., 2012), which was in agreement with our findings. However, fast freezing (3.78\%) resulted in a significantly lower thaw/purge loss of chicken breasts compared to slow freezing $(8.31 \%)$. Furthermore, the extended storage after thawing induced additional thaw/purge loss of frozen/thawed chicken breasts, from $4.44 \%$ on 0 day to $7.81 \%$ on 2 days $(P<0.05)$. In particular, a substantial increase in purge/thaw loss during storage after thawing was observed for chicken breasts assigned to slow freezing. Conversely, fast freezing resulted in a lower centrifugal WHC of frozen/thawed chicken breasts as compared to slow freezing $(P<$ 0.05). This could be attributed to the fact that chicken breasts assigned to fast freezing would have more free water, which was in turn released by centrifugal force. For a similar reason, centrifugal WHC of frozen/thawed chicken breasts significantly increased after 2 days of storage, although the considerable amount of thaw/purge loss already occurred at thawing process. Consequently, the results of the current study confirm that fast freezing reduces water loss of frozen chicken meat during thawing process. Furthermore, it also indicates that slow freezing results in not only excessive water loss upon thawing, but also continued purge fluid during refrigerated storage after thawing.

\subsection{Color characteristics}

The effects of probiotic supplementation and fast freezing on color characteristics of frozen/thawed chicken breasts on 0 and 2 days after thawing are shown in Table 2. 
No interactions between three main effects on CIE L* (lightness), a* (redness), b* (yellowness) and hue angle (discoloration) were found $(P>0.05)$. There was no significant difference in yellowness of all frozen/thawed chicken breasts. Probiotic supplementation slightly decreased redness and increased hue angle of frozen/thawed chicken breasts $(P<0.05)$. However, the differences between chicken breasts was numerically small and thus practically less meaningful. Similarly, previous studies have reported that Bacillus subtilis feeding had no influence on color characteristics of chicken breasts (Kim et al., 2016; Pelicano et al., 2003, 2005; Park \& Kim, 2014; Zhang et al., 2012). The extended storage after thawing slightly increased the lightness of frozen/thawed chicken breast muscle $(P<0.05)$. The change in lightness of meat during storage could be affected by water migration and/or distribution through muscle structure alteration (Joo, Kauffman, Kim, \& Park, 1999; Mortensen et al., 2006). According to Qiao, Flectcher, Smith, and Northcutt (2001), lightness of chicken breast muscle had a negative correlation with WHC $(r=-0.905, P=0.0008)$. Considering the increased thaw/purge loss during refrigerated storage after thawing (Table 1), water migration from intramuscular space to outside could affect light reflectance of surface on frozen/thawed chicken breast muscles, resulting in the increased lightness (Farouk, Wieliczko, \& Merts, 2004).

\subsection{Lipid content}

Lipid contents of breast muscles from control and probiotic chicken groups were 3.42 and $2.95 \mathrm{~g} / 100 \mathrm{~g}$, respectively $(P>0.05$; Table 3$)$. According to Santoso, Tanaka, and Ohtani (1995), Bacillus subtilis supplementation affected abdominal fat accumulation rather than intramuscular fat content, which could support our finding. 
The lipid content of frozen/thawed chicken breasts was unaffected by fast freezing rate, storage period and their interaction as expected $(P>0.05)$.

\subsection{Lipid oxidation}

The effects of probiotic supplementation and fast freezing on lipid oxidation (POV and TBARS) of frozen/thawed chicken breasts on 0 and 2 days after thawing are presented in Fig. 2 and 3, respectively. The breast muscles from probiotic chicken group (2.30 meq peroxides $/ \mathrm{kg}$ fat) had a significantly lower POV than those from control chicken group (2.75 meq peroxides/kg fat) (Fig. 2a). In addition, POV of chicken breasts assigned to slow freezing rate decreased after 2 days of storage $(P<$ 0.05; Fig. 2b), whereas POV of chicken breasts assigned to fast freezing rate remained unchanged $(P>0.05)$.

In terms of TBARS value of frozen/thawed chicken breasts, a three-way interaction among three main effects was found $(P<0.05$; Fig. 3). The breasts from control chicken group assigned to slow freezing rate exhibited the highest TBARS value $(P<0.05)$, regardless storage time after thawing. Immediately after thawing $(0$ day), the breasts from probiotic chicken group showed a significantly lower TBARS value than those from control chicken group. On 2 days after thawing, however, a significant increase in TBARS value was observed for breasts from probiotic chicken group assigned to slow freezing rate. This results could be explained by a decrease in primary lipid oxidation products, which was determined by POV (Fig. 2a). Further, breast muscles from probiotic chicken group assigned to fast freezing rate showed a consistently lower TBARS value compared to the other frozen/thawed chicken breasts $(P<0.05)$. Taken together, our findings indicate that probiotic supplementation could 
substantially prevent the formation of primary and secondary oxidation products. Moreover, fast freezing could delay the accumulation of secondary oxidation products upon thawing and/or following refrigerated storage after thawing.

In general, remaining unfrozen water in frozen meat products can possibly induce primary lipid oxidation during frozen storage, and subsequently, secondary lipid oxidation occurs during thawing (Leygonie et al., 2012). For this reason, numerous studies mostly focused on the effect of frozen storage temperature and/or duration on lipid oxidation of frozen chicken meat (Botsoglou, Fletouris, Florou-Paneri, Christaki, \& Spais, 2003; Grau, Guardiola, Grimpa, Barroeta, \& Codony, 2001; Selani, Contreras-Castillo, Shirahigue, Gallo, Plata-Oviedo, \& Montes-Villanueva, 2011; Soyer et al., 2010). In our current study, the results indicate that freezing rate could affect the extent of lipid oxidation of frozen/thawed chicken meat. This observation was likely attributed to the fact that fast freezing could minimize the cryo-damages to muscle cells through the formation of intracellular ice crystals. This could inhibit the release of pro-oxidants from muscle cells, such as mitochondrial and lysosomal enzymes and heme (Leygonie et al., 2012). Conversely, Tomás and Añón (1990) reported that fast freezing had no impact on lipid oxidation of frozen/thawed chicken breast muscle, but the precise information of freezing rate was not provided in the literature. To confirm the given positive effect of fast freezing on lipid oxidation of frozen/thawed meat, further studies determining the release of pro-oxidants components from muscle cells under different freezing rates would be warranted.

Previously, we reported no impact of Bacillus subtilis feeding on lipid oxidation of chicken breasts during 5 days of postmortem storage (Kim et al., 2016). However, in this current study, the observed antioxidant effect of probiotic supplementation might 
be associated with the additional freezing and thawing process. Ali (2010) reported that breasts from Bacillus subtilis fed chicken showed a significantly lower TBARS value during 8 days of storage compared to those from non-probiotic-feeding group $(P<$ 0.05). In addition, the antioxidant effect of other microbial species feeding on lipid oxidation, including Saccharomyces cerevisiae (Aksu, Karaoğlu, Esenbuğa, Kaya, Macit, \& Ockerman, 2005; Zhang et al., 2005) and Aspergillus spp. (Saleh, Eid, Ebeid, Kamizono, Ohtsuka, \& Hayashi, 2011) has been reported. While the obvious inhibitory mechanisms by which microbial probiotic supplementation reduces chicken muscle lipid oxidation has not been fully understood, few studies suggested that a reduction in fat accumulation (Aksu et al., 2005), different depositions of fatty acids (Zhang et al., 2005), and/or production of antioxidant substance (e.g. muscle $\alpha$-tocopherol) (Saleh et al., 2011) could be related to the given antioxidant effect of probiotic feeding. Thus, further studies evaluating fatty acid composition and antioxidant substance accumulation in muscle from probiotic fed chickens would provide more information to understand the mechanism underlying the antioxidant effect of probiotic supplementation.

\subsection{Phospholipid content}

The phospholipid content of frozen/thawed chicken breast muscles was affected by probiotic supplementation, freezing rate and storage period, respectively $(P<0.05$; Table 3). The muscles from probiotic chicken group (6.89 g/100 g fat) had a higher phospholipid content compared to those from control chicken group (3.65 g/100 g fat) $(P<0.05)$. This observation could imply that probiotic supplementation might affect

fatty acid synthesis in chicken muscle. In fact, Santoso et al. (1995) reported that 
Bacillus subtilis feeding influenced the amounts of serum and muscle phospholipids.

Slow freezing significantly reduced the phospholipid content of frozen/thawed chicken breasts, as compared to fast freezing rate (Table 3). In previous studies, a change in phospholipid content of chicken meat has been extensively evaluated as an indicator of lipid oxidation. Those studies found that a reduction in phospholipids during frozen storage was observed due to phospholipid oxidation and/or lipolytic degradation (Soyer et al., 2010; Pikul, Leszczynski, \& Kummerow, 1984). According to Pikul et al. (1984), approximately $90 \%$ of malondialdehyde accumulation in chicken muscle, which was determined by TBARS method, was derived from phospholipids since chicken muscle contains high amount of polyunsaturated fatty acids in phospholipids that are highly prone to oxidation (Soyer et al., 2010). In this regard, it would be reasonable to postulate that fast freezing could affect the maintenance of phospholipid content, which would result in the similar preventive effect against primary and secondary lipid oxidation as previously discussed. After 2 days of storage, however, phospholipid content of frozen/thawed breasts increased from 4.50 to 6.04 $\mathrm{g} / 100$ fat $(\mathrm{P}<0.05)$. This increment might be related to a decrease in other lipid components, such as triglycerides or a reduction in extractability of oxidized lipid components in chloroform/methanol solvent used for fat extraction in the current study (Igene, Pearson, Merkel, \& Coleman, 1979). Further studies determining the effect of display storage on phospholipid content along with detailed fatty acid profiles of chicken breasts would be warranted.

\subsection{Nonheme iron content}

The nonheme iron content of frozen/thawed chicken breast muscles was affected 
by only probiotic supplementation $(P<0.05$; Table 3$)$, where the breasts from probiotic chicken group $(0.078 \mathrm{mg} / 100 \mathrm{~g})$ had a significantly lower nonheme iron content than those from control chicken group $(0.199 \mathrm{mg} / 100 \mathrm{~g})$. Previously, Min, Nam, Cordray, and Ahn (2008) reported that raw chicken breast muscle contained $0.130 \mathrm{mg} / 100 \mathrm{~g}$, which was a similar range to our result, and suggested that an increase in free ionic iron, namely nonheme iron, greatly accelerated lipid oxidation. According to Rhee, Ziprin, and Ordonze (1987), nonheme plays a prooxidative role in catalyzing the hydroperoxides, resulting in secondary oxidation products. While there has been no available literature on the effect of probiotic supplementation on iron content and status in chicken muscle, our results suggest that the probiotic supplementation could be involved in the reduced formation of nonheme iron, resulting in an increase in lipid oxidation stability of breast muscles, in parts. Further studies determining the effect of probiotic feeding on initial heme/nonheme iron contents in chicken breasts and their changes under oxidative conditions would be warranted.

\section{Conclusion}

The results from our study found that probiotic supplementation had a significant inhibitory effect on lipid oxidation of frozen/thawed chicken breasts. Moreover, fast freezing considerably reduced thaw/purge loss and suppressed the formation of primary and secondary lipid oxidation products of frozen/thawed chicken breasts. Despite high phospholipid content, it is of interest to note that probiotic supplementation prevented the formation of both primary and secondary oxidation products. The observed positive impact of probiotic supplementation could result in leading a synergistic effect when coupling with fast freezing. 
In conclusion, our results suggest that probiotic supplementation coupled with fast freezing could effectively minimize oxidative quality deterioration and improve WHC of frozen/thawed chicken breasts. Further studies on determining underlying inhibition mechanisms on lipid oxidation by probiotic supplementation should be warranted.

\section{Acknowledgements}

Thanks are given to Derico Setyabrata, Danyi Ma, Moriah Penick, Brandon Meyers, Gary Waters, and Blaine Brown in the Meat Science Laboratory at Purdue University for assistance with sample and data collection. Mention of trade names or commercial products in this article is solely for the purpose of providing specific information and does not imply recommendation or endorsement of the USDA. The USDA is an equal opportunity provider and employer.

\section{Conflicts of interest}

The authors declare that there are no conflicts of interest.

\section{References}

1. Ahn, D. U., Wolfe, F. H., \& Sim, J. S. (1993). Three methods for determining nonheme iron in turkey meat. Journal of Food Science, 58, 288-291.

2. Aksu, M. İ., Karaoğlu, M., Esenbuğa, N., Kaya, M., Macit, M., \& Ockerman, H. W. (2005). Effect of a dietary probiotic on some quality characteristics of raw broiler drumsticks and breast meat. Journal of Muscle Foods, 16, 306-317.

3. Ali, F. H. M. (2010). "Probiotics feed supplement" to improve quality of broiler 
chicken carcasses. World Journal of Dairy and Food Sciences, 5, 93-99.

4. Ali, S., Zhang, W., Rajput, N., Khan, M. A., Li, C. B., \& Zhou, G. H. (2015). Effect of multiple freeze-thaw cycles on the quality of chicken breast meat. Food Chemistry, 173, 808-814.

5. AMSA (2012). Meat color measurement guidelines. Champaign, IL, USA: American Meat Science Association.

6. Añón, M. C. \& Calvelo, A. (1980). Freezing rate effects on the drip loss of frozen beef. Meat Science, 4, 1-14.

7. Botsoglou, N. A., Fletouris, D. J., Florou-Paneri, P., Christaki, E., \& Spais, A. B. (2003). Inhibition of lipid oxidation in long-term frozen stored chicken meat by dietary oregano essential oil and $\alpha$-tocopheryl acetate supplementation. Food Research International, 36, 207-213.

8. Buege, J. A. \& Aust, S. D. (1978). Microsomal lipid peroxidation. Methods in Enzymology, 30, 302-310.

9. Cheng, L., Sun, D. W., Zhu, Z., \& Zhang, Z. (2015). Emerging techniques for assisting and accelerating food freezing processes - a review of recent research progresses. Critical Reviews in Food Science and Nutrition, 26. $10.1080 / 10408398.2015 .1004569$

10. Eymard, S., Carcouët, E., Rochet, M., Dumay, J., Chopin, C., \& Genot, C. (2005). Development of lipid oxidation during manufacturing of horse mackerel surimi. Journal of the Science of Food and Agriculture, 85, 17501756.

11. Farouk, M. M., Wieliczko, K. J., \& Merts, I. (2004). Ultra-fast freezing and low storage temperatures are not necessary to maintain the functional properties of 
manufacturing beef. Meat Science, 66, 171-179.

12. Grau, A., Guardiola, F., Grimpa, S., Barroeta, A. C., \& Codony, R. (2001). Oxidative stability of dark chicken meat through frozen storage: Influence of dietary fat and $\alpha$-tocopherol and ascorbic acid supplementation. Poultry Science, $80,1630-1642$.

13. Grunert, T., Stephan, R., Ehling-Schulz, M., \& Jolher, S. (2016). Fourier Transform Infrared Spectroscopy enables rapid differentiation of fresh and frozen/thawed chicken. Food Control, 60, 361-364.

14. Igene, J. O., Pearson, A. M., Merkel, R. A., \& Coleman, T. H. (1979). Effect of frozen storage time, cooking and holding temperature upon extractable lipids and TBA values of beef and chicken. Journal of Animal Science, 49, 701-707.

15. Joo, S. T., Kauffman, R. G., Kim, B. C., \& Park, G. B. (1999). The relationship of sarcoplasmic and myofibrillar protein solubility to colour and water-holding capacity in porcine longissimus muscle. Meat Science, 52, 291-297.

16. Kabir, S. M. L. (2009). The role of probiotics in the poultry industry. International Journal of Molecular Sciences, 10, 3531-3546.

17. Kim, H. W., Yan, F. F., Hu, J. Y., Cheng, H. W., \& Kim, Y. H. B. (2016). Effects of probiotics feeding on meat quality of chicken breast during postmortem storage. Poultry Science, doi: 10.3382/ps/pew055

18. Kim, Y. H. B., Liesse, C., Kemp, R., \& Balan, P. (2015). Evaluation of combined effects of ageing period and freezing rate on quality attributes of beef loins. Meat Science, 110, 40-45.

19. Lee, C. M., Trevino, B., \& Chaiyawat, M. (1996). A simple and rapid solvent extraction method for determining total lipids in fish tissue. Journal of AOAC 
International, 79, 487-492.

20. Leygonie, C., Britz, T. J., \& Hoffman, L. C. (2012). Impact of freezing and thawing on the quality of meat: review. Meat Science, 91, 93-98.

21. Li, B. \& Sun, D. W. (2002). Novel methods for rapid freezing and thawing of foods - a review. Journal of Food Engineering, 54, 175-182.

22. Liu, X., Yan, H., LV, L., Xu, Q., Yin, C., Zhang, K., Wang, P., \& Hu, J. (2012). Growth performance and meat quality of broiler chickens supplemented with Bacillus licheniformis in drinking water. Asian-Australasian Journal of Animal Sciences, 25, 682-689.

23. Min, B., Nam, K. C., Cordray, J., \& Ahn, D. U. (2008). Endogenous factors affecting oxidative stability of beef loin, pork loin, and chicken breast and thigh meats. Journal of Food Science, 73, C439-C446.

24. Mortensen, M., Andersen, H. J., Engelsen, S. B., \& Bertram, H. C. (2006). Effect of freezing temperature, thawing and cooking rate on water distribution in two pork qualities. Meat Science, 72, 34-42.

25. NRC. (1994). Nutrient Requirements of Poultry. 9th rev. ed. Natl. Acad. Press, Ashington, DC.

26. Park, J. H. \& Kim, I. H. (2014). Supplemental effect of probiotic Bacillus subtilis B2A on productivity, organ weight, intestinal Salmonella microflora, and breast meat quality of growing broiler chicks. Poultry, Science, 93, 1-6.

27. Pelicano, E. R. L., Souza, P. A., Souza H. B. A., Oba, A., Norkus, E. A., Kodawara, L. M., \& Lima T. M. A. (2003). Effect of different probiotics on broiler carcass and meat quality. Brazilian Journal of Poultry Science, 5, 207214. 
28. Pelicano, E. R. L., Souza, P. A., Souza, H. B. A., Oba, A., Boiago, M. M., Zeola, N. M. B. L., Scatolini, A. M., Bertanha, V. A., \& Lima, T. M. A. (2005). Carcass and cut yields and meat qualitative tratis of broilers fed diets containing probiotics and prebiotics. Brazilian Journal of Poultry Science, 7, 169-175.

29. Pikul, J., Leszczynski, D. E., \& Kummerow, F. A. (1984). Relative role of phospholipids, triacylglycerols, and cholesterol esters on malonaldehyde formation in fat extracted from chicken meat. Journal of Food Science, 49, 704-708.

30. Qiao, M., Fletcher, D. L., Smith, D. P., \& Northcutt, J. K. (2001). The effect of broiler breast meat color on $\mathrm{pH}$, moisture, water-holding capacity, and emulsification capacity. Poultry Science, 80, 676-680.

31. Rhee, K. S., Ziprin, Y. A., \& Ordonez, G. (1987). Catalysis of lipid oxidation in raw and cooked beef by metmyoglobin $-\mathrm{H}_{2} \mathrm{O}_{2}$, nonheme iron, and enzyme systems. Journal of Agricultural Food and Chemistry, 35, 1013-1017.

32. Saleh, A. A., Eid, Y. Z., Ebeid, T. A., Kamizono, T., Ohtsuka, A., \& Hayashi, K. (2011). Effects of feeding Aspergillus Awamori and Aspergillus Niger on growth performance and meat quality in broiler chickens. Journal of Poultry Science, 48. 201-206.

33. Santoso, U., Tanaka, K., \& Ohtani, S. (1995). Effect of dried Bacillus subtilis culture on growth, body composition and hepatic lipogenic enzyme activity in female broiler chicks. British Journal of Nutrition, 74, 523-529.

34. Selani, M. M., Contreras-Castillo, C. J., Shirahigue, L. D., Gallo, C. R., PlataOviedo, M., \& Montes-Villanueva, N. D. (2011). Wine industry residues 
extracts as natural antioxidants in raw and cooked chicken meat during frozen storage. Meat Science, 88, 397-403.

35. Shantha, N. C. \& Decker, E. A. (1994). Rapid, sensitive, iron-based spectrophotometric methods for determination of peroxide values of food lipids. Journal of AOAC International, 77, 421-424.

36. Soyer, A., Özalp, B., Dalmış, Ü., \& Bilgin, V. (2010). Effects of freezing temperature and duration of frozen storage on lipid and protein oxidation in chicken meat. Food Chemistry, 120, 1025-1030.

37. Stewart, J. C. M. (1980). Colorimetric determination of phospholipids with ammonium ferrothiocyanate. Analytical Biochemistry, 104, 10-14.

38. Tomás, M. C. \& Añón, M. C. (1990). Study on the influence of freezing rate on lipid oxidation in fish (salmon) and chicken breast muscles. International Journal of Food Science and Technology, 25, 718-721.

39. Zhang, A. W., Lee, B. D., Lee, S. K., Lee, K. W., An, G. H., Song, K. B., \& Lee, C. H. (2005). Effects of yeast (Saccharomyces cerevisiae) cell components on growth performance, meat quality, and ileal mucosa development of broiler chicks. Poultry Science, 84, 1015-1021.

40. Zhang, Z. F., Zhou, T. X., Ao, X., \& Kim, I. H. (2012). Effects of $\beta$-glucan and Bacillus subtilis on growth performance, blood profiles, relative organ weight and meat quality in broilers fed maize-soybean meal based diets. Livestock Science, 150, 419-424.

41. Zhou, X., Wang, Y., Gu, Q., \& Li, W. (2010). Effect of dietary probiotic, Bacillus coagulans, on growth performance, chemical composition, and meat quality of Guangxi yellow chicken. Poultry Science, 89, 588-593. 
Table 1. Effect of probiotic supplementation, freezing rate, and storage period on $\mathrm{pH}$ and water-holding capacity (WHC) of chicken breasts

\begin{tabular}{|c|c|c|c|c|c|}
\hline \multicolumn{3}{|c|}{ Main effects } & \multirow[b]{2}{*}{$\mathrm{pH}$ value } & \multicolumn{2}{|l|}{ WHC (\%) } \\
\hline $\begin{array}{l}\text { Probiotic } \\
\text { feeding }\end{array}$ & $\begin{array}{l}\text { Freezing } \\
\text { rate }^{\mathrm{B}}\end{array}$ & $\begin{array}{l}\text { Storage } \\
\text { period }^{C}\end{array}$ & & Thaw/purge loss & Centrifugal $\mathrm{WHC}^{\mathrm{D}}$ \\
\hline \multirow{4}{*}{$\begin{array}{l}\text { Control } \\
\text { group }\end{array}$} & Fast & 0 day & 6.13 & 3.60 & 75.80 \\
\hline & & 2 days & 5.94 & 4.62 & 77.32 \\
\hline & Slow & 0 day & 6.11 & 5.30 & 78.73 \\
\hline & & 2 days & 5.91 & 11.37 & 82.78 \\
\hline \multirow{4}{*}{$\begin{array}{l}\text { Probiotic } \\
\text { group }\end{array}$} & Fast & 0 day & 5.94 & 2.73 & 74.83 \\
\hline & & 2 days & 5.87 & 4.84 & 82.15 \\
\hline & Slow & 0 day & 5.92 & 6.14 & 78.49 \\
\hline & & 2 days & 5.92 & 10.43 & 81.67 \\
\hline \multicolumn{3}{|c|}{$\mathrm{SEM}^{\mathrm{E}}$} & 0.749 & 1.264 & 1.853 \\
\hline \multicolumn{6}{|c|}{ Control vs probiotic } \\
\hline \multicolumn{3}{|c|}{ Control group } & $6.02 \mathrm{a}$ & 6.22 & 78.66 \\
\hline \multicolumn{3}{|c|}{ Probiotic group } & $5.91 b$ & 6.03 & 79.28 \\
\hline \multicolumn{6}{|c|}{ Slow freezing vs fast freezing } \\
\hline \multicolumn{3}{|c|}{ Slow freezing } & 5.96 & $8.31 \mathrm{a}$ & $80.42 \mathrm{a}$ \\
\hline \multicolumn{3}{|c|}{ Fast freezing } & 5.97 & $3.78 b$ & $77.53 b$ \\
\hline \multicolumn{6}{|c|}{ O day storage vs 2 days storage } \\
\hline \multicolumn{3}{|c|}{0 day of storage after thawing } & $6.02 \mathrm{a}$ & $4.44 b$ & $76.96 b$ \\
\hline \multicolumn{3}{|c|}{2 days of storage after thawing } & $5.91 b$ & $7.81 \mathrm{a}$ & $80.98 \mathrm{a}$ \\
\hline \multicolumn{6}{|c|}{ Significance of main effects and interactions (P value) } \\
\hline \multicolumn{3}{|c|}{ Probiotic supplement effect $(\mathrm{P})$} & 0.0052 & $N S^{\mathrm{F}}$ & NS \\
\hline \multicolumn{3}{|c|}{ Freezing rate effect $(\mathrm{F})$} & NS & $<0.0001$ & 0.0260 \\
\hline \multicolumn{3}{|c|}{ Storage period effect $(\mathrm{S})$} & 0.0036 & $<0.0001$ & 0.0027 \\
\hline \multicolumn{3}{|c|}{$\mathrm{P} \times \mathrm{F}$} & NS & NS & NS \\
\hline \multicolumn{3}{|l|}{$\mathrm{P} \times \mathrm{S}$} & 0.0444 & NS & NS \\
\hline \multicolumn{3}{|l|}{$\mathrm{F} \times \mathrm{S}$} & NS & 0.0082 & NS \\
\hline \multicolumn{3}{|c|}{$\mathrm{P} \times \mathrm{F} \times \mathrm{S}$} & NS & NS & $\mathrm{NS}$ \\
\hline $\begin{array}{l}{ }^{\mathrm{A}} \text { Probiotic fe } \\
\text { containing } B c \\
{ }^{{ }^{\mathrm{B}}} \text { Freezing rat } \\
\text { in a liquid nit } \\
{ }^{\mathrm{C}} \text { Storage peri } \\
{ }^{\mathrm{D}} \text { High value } \\
{ }^{\mathrm{E}} \text { SEM: stand } \\
{ }^{\mathrm{F}} \text { NS: non-sig } \\
\text { a,b Different }\end{array}$ & $\begin{array}{l}\text { ding: basal d } \\
\text { illus subtilis) } \\
\text { : slow freezin } \\
\text { ogen chamber } \\
\text { d: storage peri } \\
\text { eans an excell } \\
\text { d error of the } \\
\text { ficance. }\end{array}$ & $\begin{array}{l}\text { for control } \\
\text { r probiotic } \mathrm{g} \\
\text { vas perform } \\
\left.70{ }^{\circ} \mathrm{C}\right) . \\
\text { s in a } 2{ }^{\circ} \mathrm{C} \mathrm{c} \\
\text { t WHC agai } \\
\text { an. }\end{array}$ & $\begin{array}{l}\text { oup and basa } \\
\text { a }-30{ }^{\circ} \mathrm{C} \text { co } \\
\text { centrifugal fo }\end{array}$ & $\begin{array}{l}\text { th plus } 250 \mathrm{ppm} \mathrm{Spo} \\
\text { tional freezer, wherea } \\
\text { fter thawing. }\end{array}$ & $\begin{array}{l}\text { lin }\left(1.0 \times 10^{6} \mathrm{cfu} / \mathrm{g} \text { feed }\right. \\
\text { fast freezing was conducted }\end{array}$ \\
\hline
\end{tabular}


Table 2. Effect of probiotic supplementation, freezing rate, and storage period on color characteristics of chicken breasts

\begin{tabular}{|c|c|c|c|c|c|c|}
\hline \multicolumn{3}{|c|}{ Main effects } & \multicolumn{4}{|c|}{ Color characteristics } \\
\hline $\begin{array}{l}\text { Probiotic } \\
\text { feeding }^{A}\end{array}$ & $\begin{array}{l}\text { Freezing } \\
\text { rate }^{\mathrm{B}}\end{array}$ & $\begin{array}{l}\text { Storage } \\
\text { period }^{C}\end{array}$ & $\begin{array}{l}\text { CIE L* } \\
\text { (lightness) }\end{array}$ & $\begin{array}{l}\text { CIE a* } \\
\text { (redness) }\end{array}$ & $\begin{array}{l}\text { CIE b* } \\
\text { (yellowness) }\end{array}$ & $\begin{array}{l}\text { Hue angle } \\
\text { (discoloration) }\end{array}$ \\
\hline \multirow{4}{*}{$\begin{array}{l}\text { Control } \\
\text { group }\end{array}$} & Fast & 0 day & 51.27 & 5.79 & 17.55 & 71.67 \\
\hline & & 2 days & 54.62 & 5.17 & 18.00 & 74.03 \\
\hline & Slow & 0 day & 52.13 & 5.85 & 17.68 & 71.70 \\
\hline & & 2 days & 54.65 & 5.35 & 17.88 & 73.33 \\
\hline \multirow{4}{*}{$\begin{array}{l}\text { Probiotic } \\
\text { group }\end{array}$} & Fast & 0 day & 54.07 & 4.73 & 17.93 & 75.27 \\
\hline & & 2 days & 54.89 & 5.24 & 18.06 & 73.84 \\
\hline & Slow & 0 day & 52.82 & 4.60 & 17.37 & 75.18 \\
\hline & & 2 days & 55.67 & 4.67 & 18.06 & 75.44 \\
\hline \multicolumn{3}{|l|}{$\mathrm{SEM}^{\mathrm{D}}$} & 1.371 & 0.651 & 0.839 & 1.899 \\
\hline \multicolumn{7}{|c|}{ Control vs probiotic } \\
\hline \multicolumn{3}{|c|}{ Control group } & 53.17 & $5.54 \mathrm{a}$ & 17.78 & $72.68 b$ \\
\hline \multicolumn{3}{|c|}{ Probiotic group } & 54.36 & $4.81 \mathrm{~b}$ & 17.85 & $74.93 \mathrm{a}$ \\
\hline \multicolumn{7}{|c|}{ Slow freezing vs fast freezing } \\
\hline \multicolumn{3}{|c|}{ Slow freezing } & 53.82 & 5.12 & 17.75 & 73.91 \\
\hline \multicolumn{3}{|c|}{ Fast freezing } & 53.71 & 5.23 & 17.88 & 73.70 \\
\hline \multicolumn{7}{|c|}{0 day storage vs 2 days storage } \\
\hline \multicolumn{3}{|c|}{0 day of storage after thawing } & $52.57 \mathrm{~b}$ & 5.24 & 17.63 & 73.45 \\
\hline \multicolumn{3}{|c|}{2 days of storage after thawing } & $54.96 \mathrm{a}$ & 5.11 & 18.00 & 74.16 \\
\hline \multicolumn{7}{|c|}{ Significance of main effects and interactions (P value) } \\
\hline \multicolumn{3}{|c|}{ Probiotic feeding effect $(\mathrm{P})$} & $N S^{\mathrm{E}}$ & 0.0306 & NS & 0.0235 \\
\hline \multicolumn{3}{|c|}{ Freezing rate effect $(\mathrm{F})$} & NS & NS & NS & NS \\
\hline \multicolumn{3}{|c|}{ Storage period effect (S) } & 0.0013 & NS & NS & NS \\
\hline \multicolumn{3}{|c|}{$\mathrm{P} \times \mathrm{F}$} & NS & NS & NS & NS \\
\hline \multicolumn{3}{|l|}{$\mathrm{P} \times \mathrm{S}$} & NS & NS & NS & NS \\
\hline \multicolumn{3}{|l|}{$\mathrm{F} \times \mathrm{S}$} & NS & NS & NS & NS \\
\hline \multicolumn{3}{|l|}{$\mathrm{P} \times \mathrm{F} \times \mathrm{S}$} & NS & NS & NS & NS \\
\hline \multicolumn{7}{|c|}{$\begin{array}{l}{ }^{A} \text { Probiotic feeding: basal diet for control group and basal diet plus } 250 \mathrm{ppm} \text { Sporulin }\left(1.0 \times 10^{6} \text { cfu/g feed }\right. \\
\text { containing Bacillus subtilis) for probiotic group. } \\
{ }^{\mathrm{B}} \text { Freezing rate: slow freezing was performed in a }-30^{\circ} \mathrm{C} \text { conventional freezer, whereas fast freezing was conducte } \\
\text { in a liquid nitrogen chamber }\left(-70^{\circ} \mathrm{C}\right) \text {. } \\
{ }^{\mathrm{C}} \text { Storage period: storage periods in a } 2{ }^{\circ} \mathrm{C} \text { cooler }(0 \text { and } 3 \text { days) after thawing. } \\
\text { DSEM: standard error of the mean. }\end{array}$} \\
\hline
\end{tabular}


Table 3. Effect of probiotic supplementation, freezing rate, and storage period on lipid, phospholipid and nonheme iron contents of chicken breasts

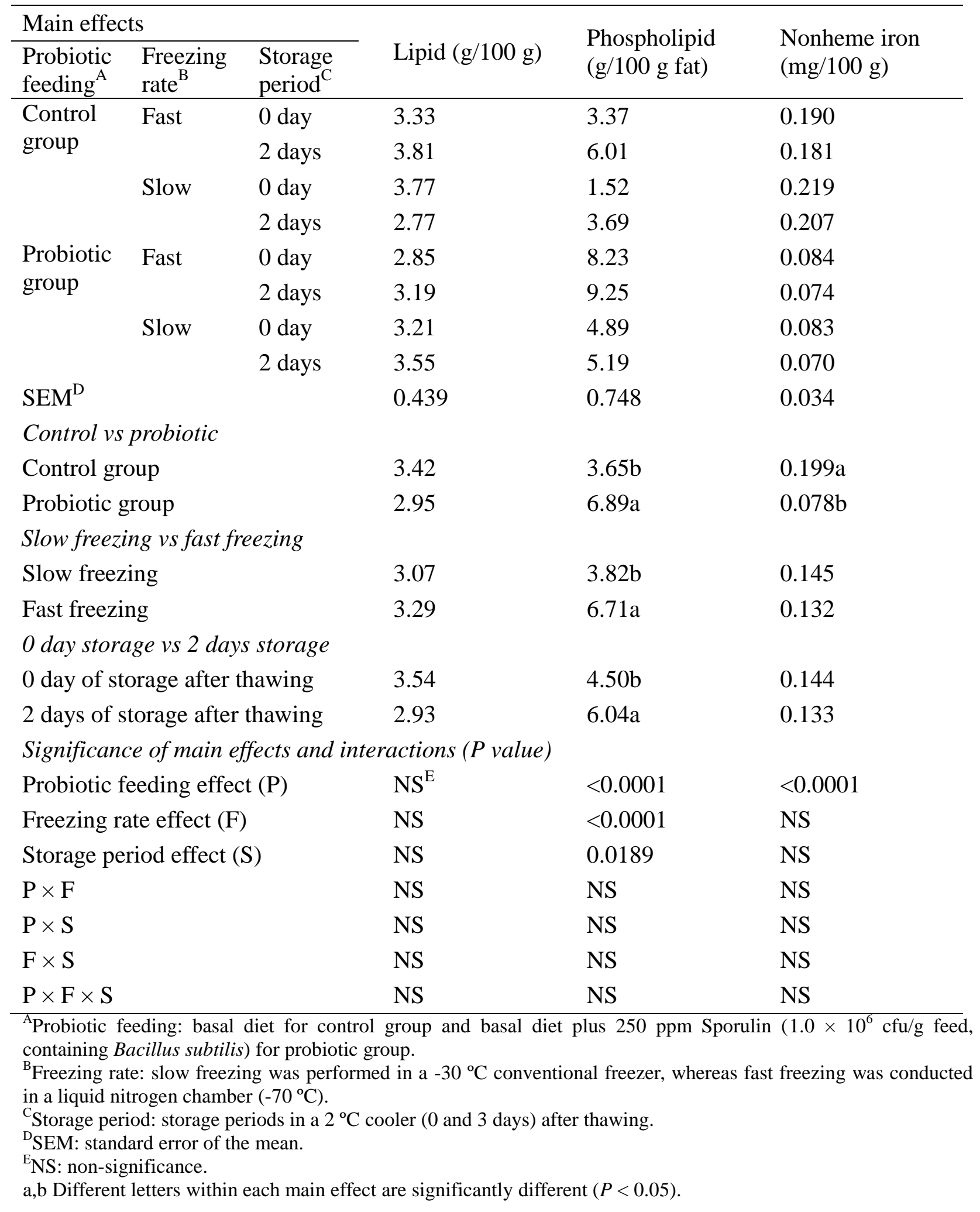




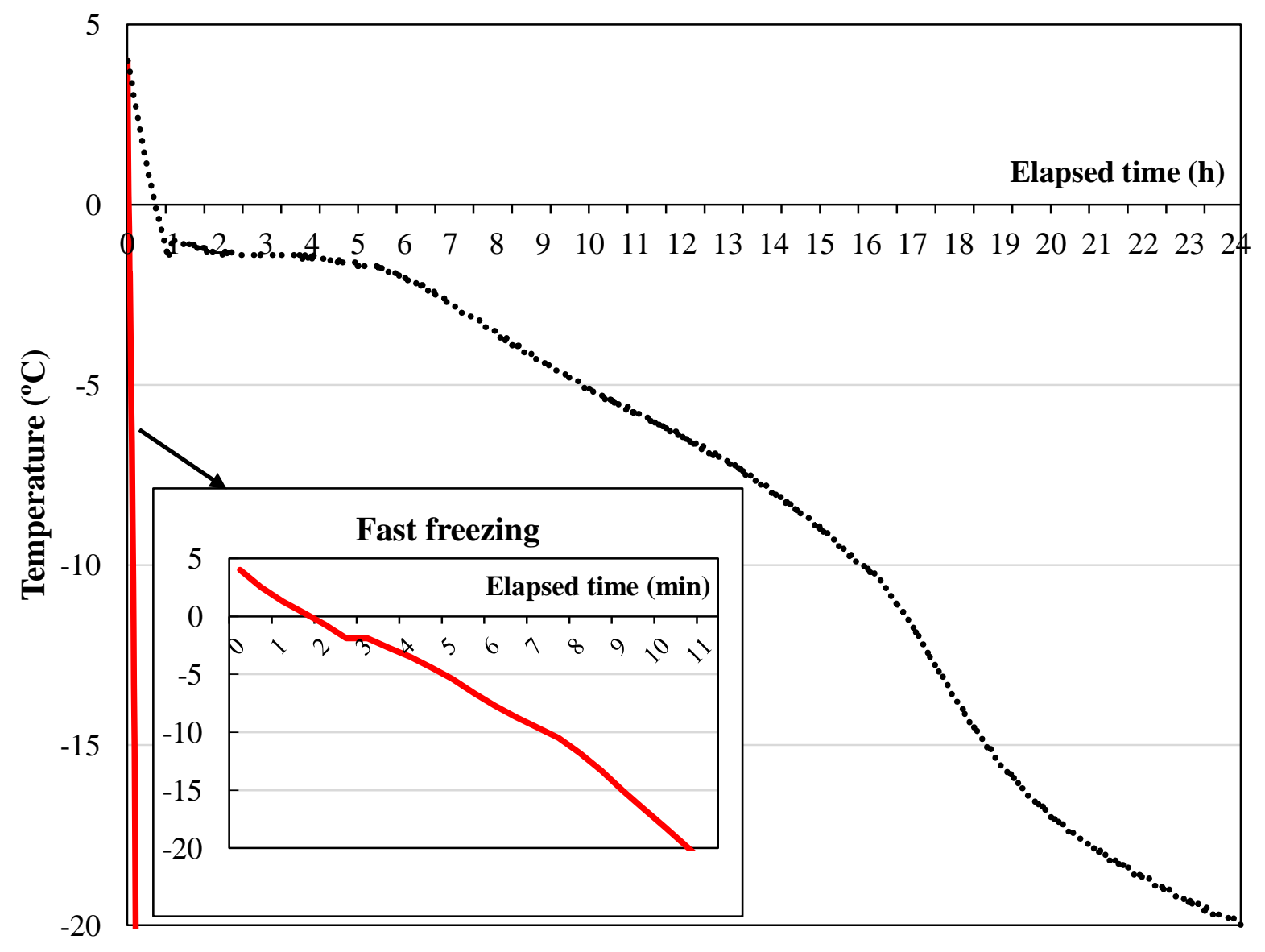

Fig. 1. Temperature decline of chicken breasts during slow and fast freezing procedures. The slow freezing was conducted in a $-\mathbf{3 0}{ }^{\circ} \mathrm{C}$ conventional freezer, while fast freezing was performed in $-\mathbf{7 0}^{\circ} \mathrm{C}$ liquid nitrogen chamber. Red solid and black dotted lines indicate temperature decline of breasts assigned to fast and slow freezing, respectively. 
(a) Probiotic supplementation effect

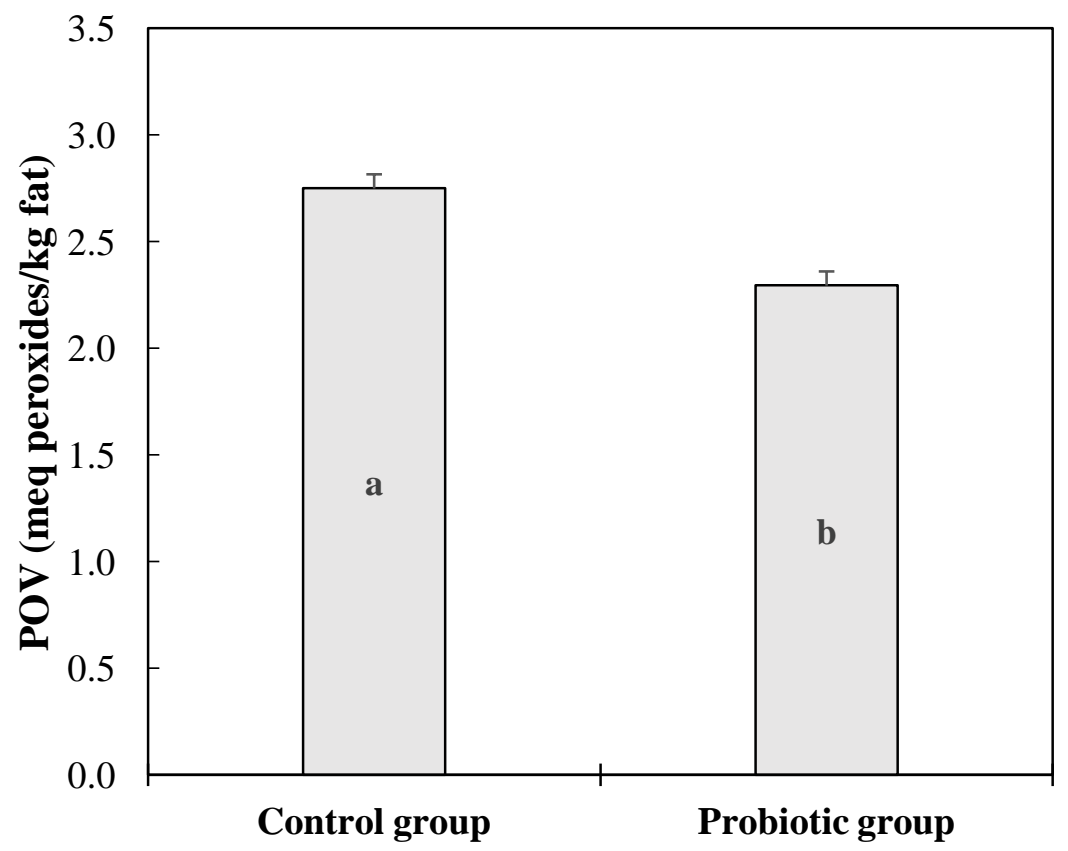

(b) Freezing rate $\times$ storage period effects

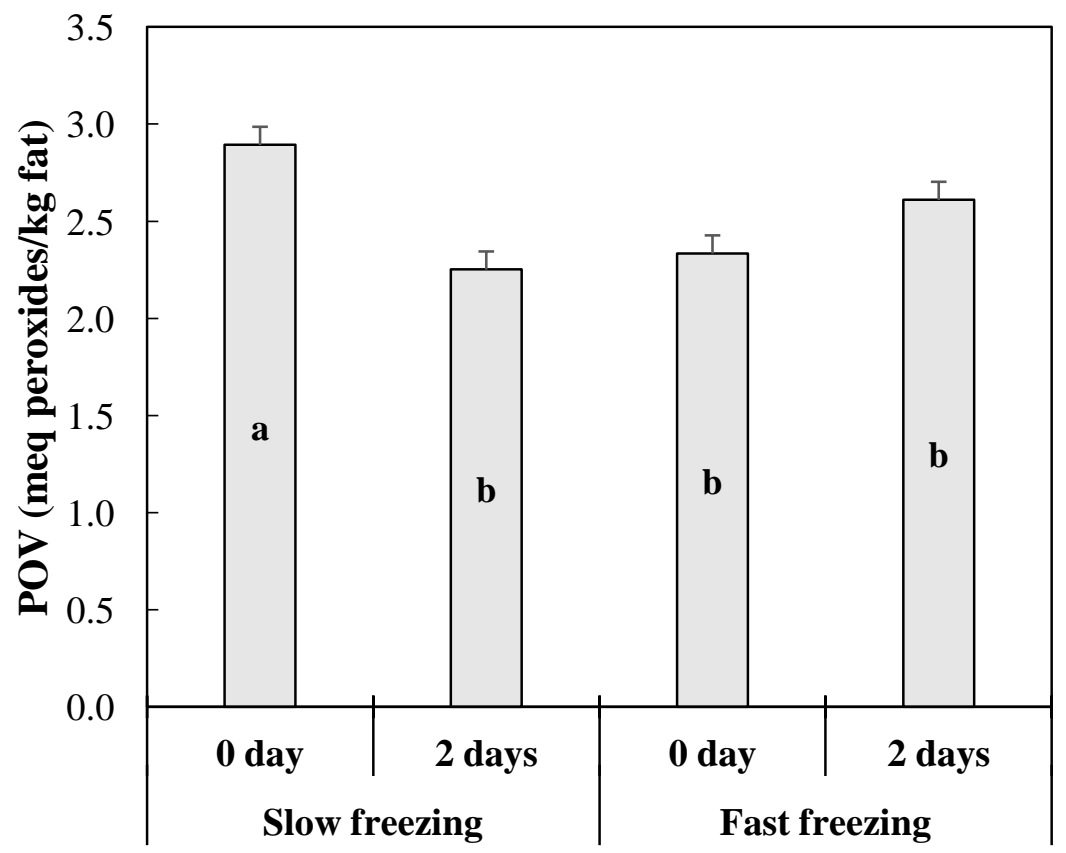

Fig. 2. Effect of probiotic supplementation, freezing rate, and storage period after thawing on peroxide value (POV) of chicken breast muscles. a,b Different letters are significantly different $(P<0.05)$. 


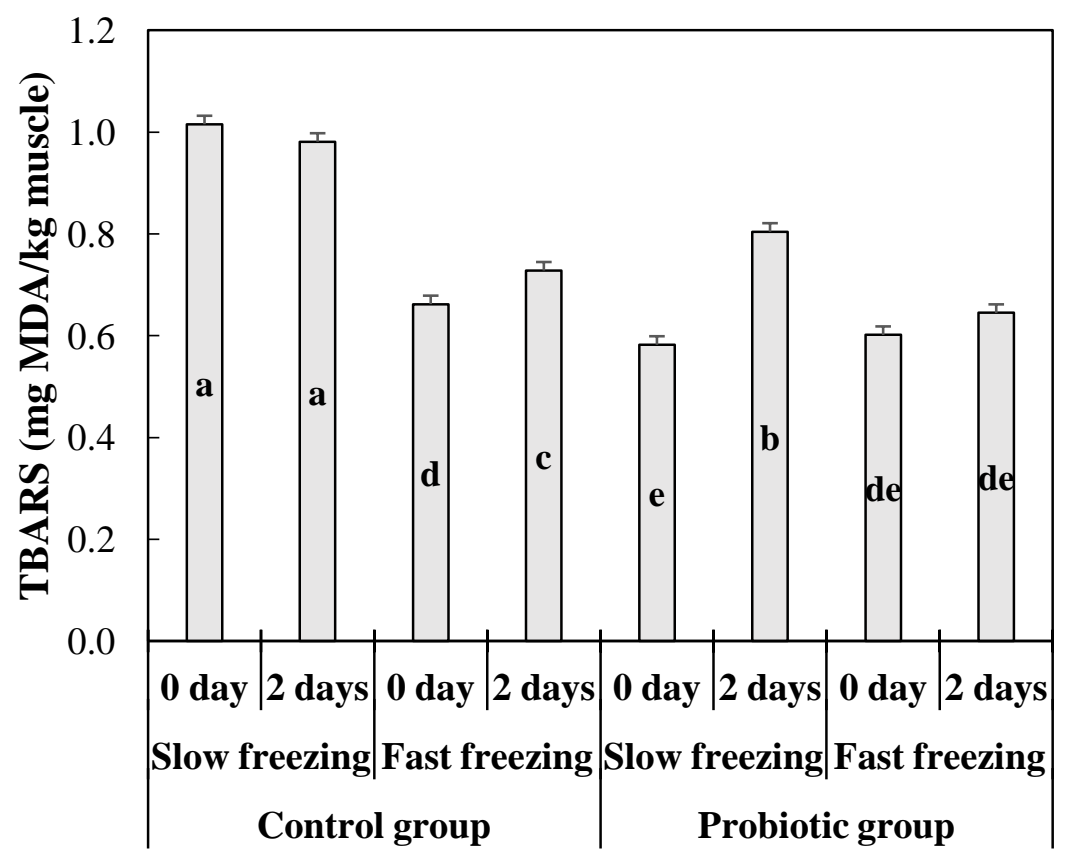

Fig. 3. Effect of probiotic feeding, freezing rate, and storage period after thawing on 2thiobarbituric reactive substances (TBARS) value of chicken breast muscles. a-e Different letters are significantly different $(P<0.05)$. 